LA-UR-91-1976

LA-UR $-91-1976$

DE91 014748

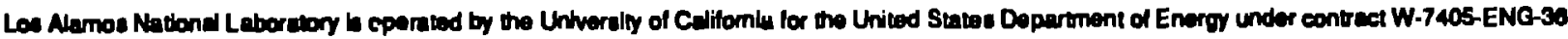

\title{
TILE: EFFECTS OF ANISOTROPY ON DYNAMIC TENSILE BEHAVIOR
}

\section{DISCLAIMER}

AUTHOR(S): S. K. Schiferl

R. F. Davidson

P. J. Maudlin

This report was prepared as an account of work sponsored by an agency of the United Siutes Government. Neither the United States (iovernment nor any agency thereof, nor any of their employees, makes any warranly, express or implied, or assumes any legal liability or responsihility for the accuracy, completeness, of usefulness of any information, apparatus, product, or process disclosed, of represents that its use would not infringe privately uwned rights. Reference herein to any specific commercial product, process or service by irude name, trademurk, manufacturer, or otherwise dues not necessarily constitute or imply its endorsement, recommendation, or favoring ly the I/nited States (jovernment or any agency thereof. The views and opinions of authors expressed herein do not necessurily stute of reflect those of the United States (iovernment or any agency thereof.

SUBMITED TO: 1991 APS Topical Conference on Shock Compression of Condensed

Matter

June 17-20, 1991

Williamsburg, Virginia

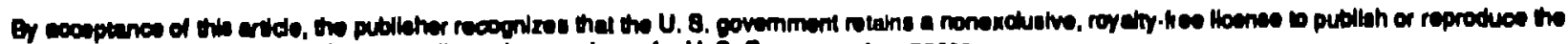

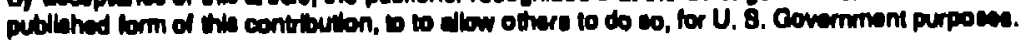

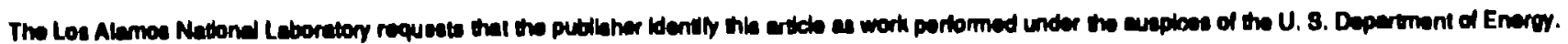

LOS AIDIñOS

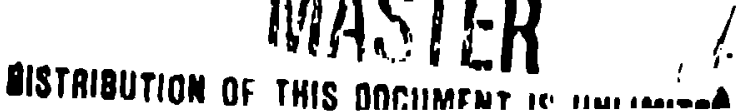




\title{
EFFECTS OF ANISOTROPY ON DYNAMIC TENSILE BEHAVIOR
}

\author{
Sheila K. Schifert. Rich F. Davidson, and Paul J. Maudlin
}

Los Alamos National Laboratory, Los Alamos, New Mexico 87545

A sability analysis for an anisotropic stretching nod is presented. We consider the particular case of a rapidly stretching otanium jet using a concinuum code to examine anisotropic plastic response in the finile-neck regime. It was found that the classical analysis (vield stength is inversely proportional wo stability) is insufficient: anisotropic jets can be more or less stable than their maximum or minimum yield stengths, depending on initial peraubations and the orientation of the anisotropy. One particular anisouropy-with the weak direction along the jet axis-appears to be generally stabilizing.

\section{INTRODUCTION}

When a metal rod is stretched, thit material becomes unstable in the sense that one or more necks eventually will appear and grow until the rod breaks. We will consider this stability problem for a paricular dymaraic case: the neck-down of a shaped-charge jet, with strain rates of the order of $10^{4}-10^{5} \mathrm{~s}^{-1}$. for an anisotropic material. The necking problem first was treat. ed for a nonstretching capillary jet by Rayleigh.' and the general nuid protiem has been treated extensively in the literature. Rayleigh's expression for perturbucion growth lias two pars: a parameter, $\Phi=T / p^{3}$, and a factor depending on the perturtation wavelength. Here, $T$ is the surface tension, $p$ is une density, and $a$ is the radius: $\Phi$ has units of (ume)-2. Eariy wort on the stability problem for a stretching solid rod, which has some math. ematical similarities to the fluid case, was done by Chou and Carteone ${ }^{2}$ and Walsh' usin/s boch analyucal and computer simulation methods. An initial radial velocity gradient was added by Romero. 4 If $T$ is replaced by $Y_{2}$ where $Y$ is the yield strength. and the stability parameter, $r$, is made dimensionleas. ${ }^{3}$ we obcain

$$
r^{2}\left(u=\sqrt{3} d \dot{e}^{2}\left(u a^{2}(0) / r .\right.\right.
$$

where $\dot{\varepsilon}$ is the axid strin-rate. Note tha the lower the yleld strength and the higher the denalty (and surin rale), the more stable the jet. As the iet stretches. $r$ decreaves. For I'<l, perturbations becoms unsuble." The anbullity is imporiank for the pen. etrition of a jet into is target: the slower the growth of perturts. tons, the longet the final jet fragenento-and longer fragunents penetrate deeper.

The above phe nomena have been seen in jet stmulations. and all but certain den ilty eifects currespond wexperimencel dima. Deneliy efrects as hamt wo lcolate because chanding the density venerally means changing the jet material. and factorn not treaked by the above analysis may be oqually importane in particu. las: pes of zircernium and ticanium (makerials with a hexagonal. cluse packed (ncp) cryalal anucturel appear to be more auble than their (loiv) densities would indicale. One possible mbilling factor is anis siropy, and plastic anisotroples for hep materials can be very large. For example, yield anisouropies can be greater than 2:1. and $R$ values (the ratio of plastic width strain to thickness strain in a tensile test) typically range from 3-7.5 The source of this anisotropy is crystallographic texture, the preferred orientation of single-crystal grains in a polycrystalline solid. If the orientations are not random. the material will tend to be a.,sotropic because single crystals are nomally anisouropic. A strong pieferred orientation is typically the result of a large deformation ( $\varepsilon>50 \%$ )-and jet deformacions are extrordinarily large.

Our systers of interest is the stability of an axisymmetric. anisotropir jet with the properties typical of (hcp) $\alpha$-titaniun and some of its alloys. where the preferred orientations are results of a high-speed lensile deformacion. If the material can Iwin (the usual case), the well-developed jet will have a typical extrusion lexture. 6 with the "hard" directions (c-axes) of the grains pointing radially. This produces a plastic anisotropy in the e:itruded rod (or jet), with the weak direction along the axis and the strong direction radial. For comparison, we also evaluate the upposice anisolropy with the serong direction along the axis (typical of cross-rolled sheel).

In the presenk work, we invest gate the effects of these two different anisoiropies on jet stability. We use a texture code to calculate the anisormpy resulting from a set of preferrot orienta. tions. Essentally, such a calculation "sumples" an oriented collection of grains and models the sinple crystal mechenisms of slip and iwinning to produce a set of stress poinus that together define a yield surface. ${ }^{7}$ We use condnuum calculations to simulate neck growth and to follow the effect of Inildal perturbution into the nonlines. Anite-neck regime. The results of our calcuIwions indicate the and sotropy cen have al orifican effects on neck growhi, either to stabulize or wo destublitixe, depending on the nuture of the anisolropy and of ine initlal perturbations. Moreover, anisotropic atablitity is not juat a mater of the magnl. lude of the yleid strengh.

\section{PROCEDURE}

Our investigation of jet subillty consisu of two pans: (1). coxiparison of isotropic and anisotropic reaponse and (2) a suady 
of the effects of different initial rerturbations. Both isotropic and anisotropic material models were incorporated into a modified version of EPIC2.88," an explicit Lagrangian 2D finite. element code. The code modifications are described elsewhere. ${ }^{7}$

The anisotropic material was modeled from the general features of heavily cross-rolled (transversely isotropic) titanium or zirconium sheet.9 This sheet gives an $R$ value of $\sim 6.5$, which corresponds to an anisotiopy ravio of $\sigma_{z} / \sigma_{x}-1.95$. where $z$ is the through-thiskness direction and $x$ is in the plane of the sheet. Details of the yield surface, including shear strength, were obtained with a texture simulation using single-crystal properties of hep titanium at moderately high temperarures and relatively high strain rates. The yield surface was normalized by applying the texture code to a randomly oriented collection of grains, and setting the (isotropic) average yield stress to $200 \mathrm{MPa}$, a value characueristic of annealed sheet. The two strong anisotropies described in Sec. I were fitted to a standard quadratic anisotropic yield function. 10 Our two anisouropies correspond to two different intial material orienuations of the samie yield function: $0^{\circ}$ (weak direction axial) and $90^{\circ}$ (strong direction axial), where the strong. weat. and shear components are $Y=239,123$, and 217 $\mathrm{MPa}$, respectively.

Along with the anisotropic functions, we used two isotropic models, with $Y=123$ and $239 \mathrm{MPa}$, corresponding to the anisotropic weak and strong directions. Both isouropic and aniso. iropic materials were treated as elaxic-perfectly-plastic. The constant yield sur face should be applicable wo the late sages of jetting. where hardening and thermal softening compele. In addition. the first stages of necking. a lesst, probably would not viler the anisolropy significallly.

A section of the stretching jet was modeled as a cylinder fixed at one end and with the other end moving at a constant ve. locily. Necking was inj 'aled by imposing small perturbations in the outer surface of the bar. The perturbed surface was stress. free, and the end surfaces were free from shear stresses. For initial conditions, we imposed linear velocity distributions in hoth radial and axial directions.

The initial jet Gimensions and strain rate were within the norinal range for jets at the ume when necks are fira visible: the axial strain rate. ic, was $6.1 \times 10^{4}, 1$, the unrerturbed radius. $r_{0}$. was $2.13 \mathrm{~mm}{ }^{2}$ and the initial segment length. $L_{0}$. was $8.52 \mathrm{~mm}$. If the density is $4.5 \mathrm{~g} \mathrm{~cm}^{-3}$ (Utanium), the subility panmeter, $r$, ranges from $0.74-1.0$. indicatine conditions sligitly unstable for r.ck growth. The initial radid veloctty was calculaced to be $\mathrm{er} / 2$ by assumine plestic incompressibility.

We set up two different kinds of disturtances in the free sur. face of the jet. The first kind is s superposition of cosine waves:

$$
r(1)=r_{n}+\sum_{n=1}^{B} a_{n} \cos \left(2 \pi \pi \lambda_{n}\right)
$$

where $r(z)$ is the radial coordinate and $\lambda_{n}=L_{d} / n$. We consuructed two different cosine series. For the firsh, we used only four waves ( $a_{n}=0.026 \mathrm{~mm}$ for $n=1,2,4,8: a_{n}=0$ otherwise). This series corresponds to Chou and Carteone's ${ }^{2}$ initial perturbation and spans their most unstable wavelengths. For the second series, we used all eight waves $(2 n=0.026 \mathrm{~mm}$ for all $n)$. The second kind of initial disturbance is a set of random perturbations:

$$
r(z)=r_{0}+\alpha \times \operatorname{RAN}
$$

where $\alpha=0.013 \mathrm{~mm}$ and $R A N$ is a random number betweer. -1 and 1. A different seed was used to generace each set of random perturbations. These axisymmerric calculations were performed with 600 rectanģular finite elements: 6 radial elemerts $\times 100$ axial elements. This spatial resolution was well-converged when compared with a doubly fine case $(12 \times 200)$.

Finaliy. to follow the necking process, we define a grownth function:

$$
f(t)=\frac{r_{\min }(u) r_{\min }(t)}{R(t)}
$$

where $R$ is the undisturted radius. The grounh function was calculated at $1-\mu$ s intervals.

\section{RESULTS AND DISCUSSION}

The results for necking of both isotropic and anisotropic jets for different kinds of initial perturbations are shown in Figs. 1-6. For each of these simulations, we compare neck growth for fow material models: two anisotropic inodels, the first with the arong direction along the axis $\left(90^{\circ}\right)$ and the second with the weak direction along the axis $\left(0^{\circ}\right)$ and iwo isotropic models, one with a yield strength of $239 \mathrm{MPa}$ (the same as the anisotropic strong direction, and the maximum anisotropic strength) and one with a yield strength of $123 \mathrm{MPa}$ (the same as the anisotropic weak di. rection). From the classical stability analysis, the two isouropic cases should bracket the anisotropic results because the anisotropic vield strength varies betwoen 123 and $239 \mathrm{MPz}$. Thus the anisotropic $k$ ishould be, in general, more stable than the 239-MPa jet and less stable than the 123-MI'a jet.

Cur simulations show that the classical analysis is insum. cient for anisotropic effects. Figures 1 and 2 show the nect growth and jet shapes, respectively, for the four-wave cosine perturtation. The $0^{\circ}$ anisotripy ls mors stable than the 123. MPa isouropic case, even unough the anisotrople yield strength equals $123 \mathrm{MPa}$ for axial tension and is gresuer than 12] MPa for the stress states "neas" tersion encountered in ine necked reston. This extre scability musi he a result of anisotropy, not overall yield sirengeth differences. The nect disuribution is also differens for isouropic and anisotropic feus.

Figures 3 and 4 show neck growth and jel shapes for the elght. wave perturtation. Here, both anieotropic cases are gener. ally more siable than one $123 \mathrm{MPa}$ isotropy. The anisotropic 


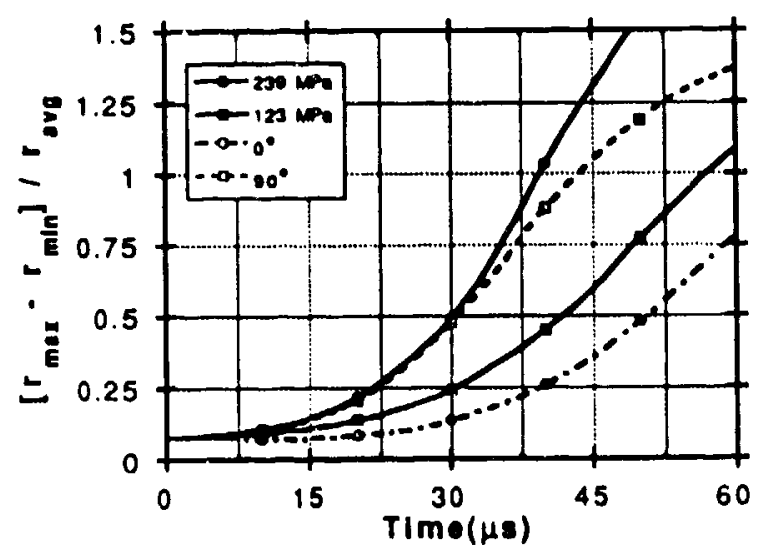

Fig. 1. Growih functions for four-wave perrurbation.
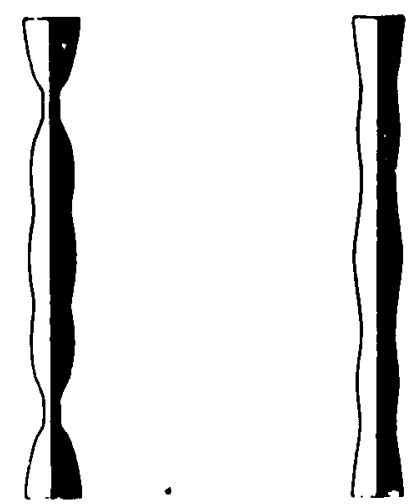

(a) $239 \mathrm{MPa}$

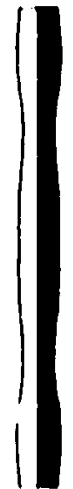

(c) $\infty^{\infty}$ (b) $123 \mathrm{MPa}$

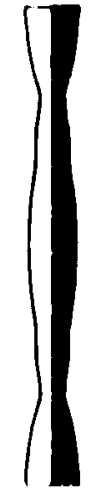

(d) $90^{\circ}$

Iitg. 2. Element ploss for neck connguration a $40 \mu$ แs: four wave perturtation.

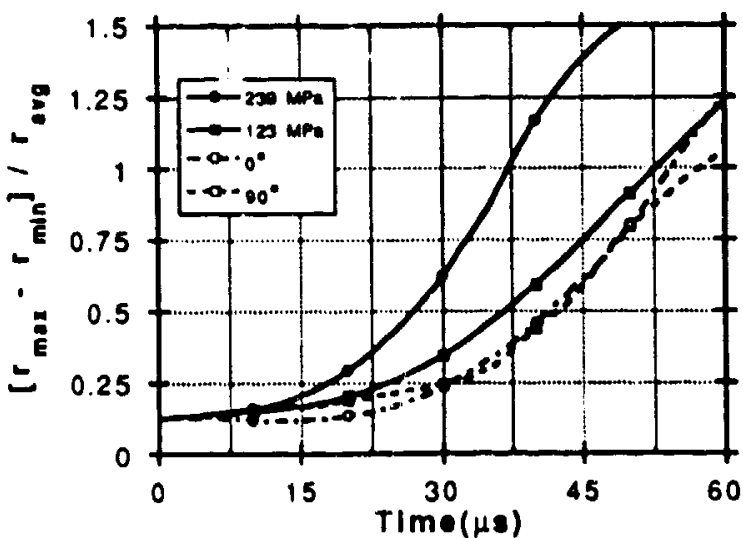

Fig. 3. Growth functions for eight-wave penurbation.

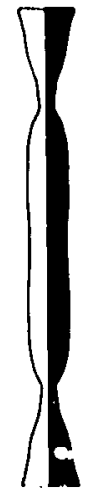

(a) $239 \mathrm{MP}$

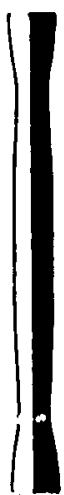

(c) $0^{\circ}$

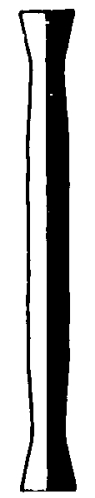

(b) $123 \mathrm{MP}$

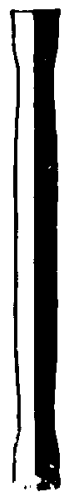

(d) $90^{\circ}$ litg. 1. lement plots for neck tonnguration as 4) $\mu \mathrm{s}$, cianli. weve perturtation 


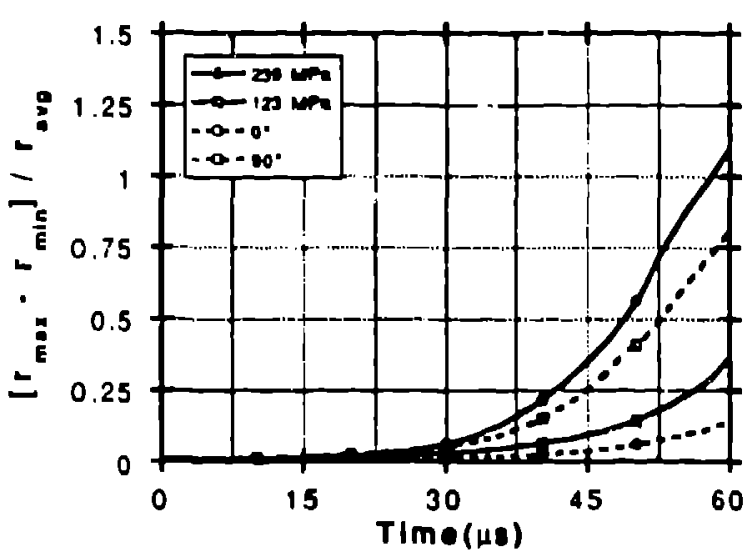

Fig. 5. Growth functions for random peiturioations (Set 1),

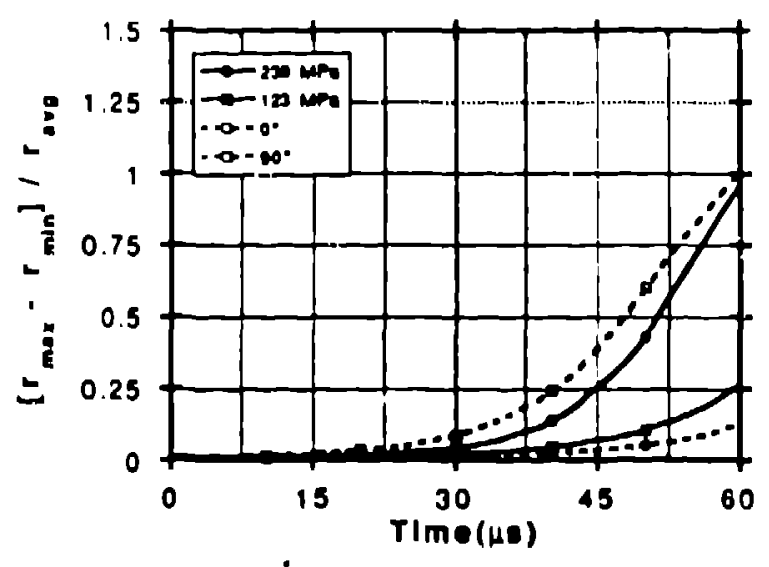

Fig. 6. Grown functions for random penurbedions (Set 2).

stability has changed significandy, whereas the lsotrople neck growth is not affecied a grificandly. (llowever, it is cles from Fing. 2 and 4 thes the isouropic neck disaribution to censidive to initial perurbestons.)

Figures $S$ and 6 show neck growh for iwo sels of random perturtations. In the Arst cese, the 900 anisotropy li consider. ably more atable then the 239 MPa isouropy. In the recond cuse. in consase, the 9xo and couropy is leas aable even though the muximum enicouropic yicld is $239 \mathrm{MP}$. The 00 anieorropy is more suble tiun ite 123 MPe looropy for both rindom set. We have celculuad other random sets. and the increased nubllity for the (10 anisotropy was repented. In addition, the on case itues lenger to be gin necking then the leotroptc caues.

These results susfeat severd special chancteritacs of and. suliopic response. Find, the clastical anjument of "lower yield

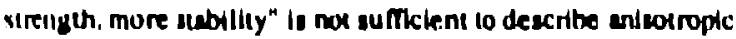
response in necking. Second, injual penurbalions have a dignir. icaus efrect on the nect growth of andsotmpic (but no isotropic) jets. (These perturbations do have a lage effect on the neck distribution of both isoropic and anisorropic jess). Finally. an anjsouropic orientation witt the weak direction of the muerial along the axis (the usual rod texnre for a twinning hep orenerial) 4 pears to sigrificandly stabilize againat necking. compared with an isceropic matertal having the same yield strength as in the anisotropic weak direction. This may be par of the extra stability seen in jess of hexagond materials.

\section{REFERENCES}

1. Lor' Rayleigh, Sciensifte Papers (Dover, New York. 1964), Vol. I.

2. P. C. Chou and J Carteone. J. Appl. Phys. 48. 4187 (1977).

3. J. M. Walsh. J. Appl. Phys. 56.1997 (1984).

4. L. A. Romero. J. Appl. Phys. 65.3006 (1989).

5. R. G. Ballinger and R. M. Pelloux, J. Nucl. Muter. 97, 231 (1981): W. F. Hosford and R. M. Cuddell, Metal Forming: Mechanics and Merallwgy (Prenuce.Hall, Englewood Culfs, New Jersey, 1983).

6. S. K. Schufert. 'Twinning. Texture, and Consutudve Relations for Explosively formed Jess" in Shock Compression of Condensed Marter - 1989. S. C. Schmidh J. N. Johnson and L. W. Davison, Eds. (North-Holland, Amslerdem, 1990). Pp 353-356.

7. S. K. Schifert and P. J. Maudlin, 'Texrure-Induced Anisxropy and High-Suain-Rute Deformation in Metals" in Shock Waves and IIigh-Strain-Ruse Phenomena in Maserlals, $M$. A. Meyer, L. E. Murr, and K. P. Staudhenmer, Eds. (M. Dekker, New Yort, 1991)

B. G. R. Johnson and R. A. Siryk, Air Force Armernent Laboneory Repon TR.86-91 (1986).

9 F. Larson and A. Zartades. Meculs and Ceramies Information Center Repon No MCIC.74-20 (1974).

10. R. Ulill, Proc. Roy. Soc. London A 193, 281 (1918) 